\title{
GCU
}

Glasgow Caledonian

University

University for the Common Good

\section{The contribution of health risk behaviors to excess mortality in American adults with chronic hepatitis $\mathrm{C}$ : a population cohort-study}

Innes, Hamish; McAuley, Andrew; Alavi, Maryam; Valerio, Heather; Goldberg, David;

Hutchinson, Sharon J.

Published in:

Hepatology

DOI:

10.1002/hep.29419

Publication date:

2018

Document Version

Author accepted manuscript

Link to publication in ResearchOnline

Citation for published version (Harvard):

Innes, H, McAuley, A, Alavi, M, Valerio, H, Goldberg, D \& Hutchinson, SJ 2018, 'The contribution of health risk

behaviors to excess mortality in American adults with chronic hepatitis C: a population cohort-study',

Hepatology, vol. 67, no. 1, pp. 97-107. https://doi.org/10.1002/hep.29419

\section{General rights}

Copyright and moral rights for the publications made accessible in the public portal are retained by the authors and/or other copyright owners and it is a condition of accessing publications that users recognise and abide by the legal requirements associated with these rights.

Take down policy

If you believe that this document breaches copyright please view our takedown policy at https://edshare.gcu.ac.uk/id/eprint/5179 for details

of how to contact us. 
TITLE: The contribution of health risk behaviours to excess mortality in American adults with chronic hepatitis C: A population cohort-study

AUTHORS: Innes $\mathrm{H}^{1,2}$, McAuley $\mathrm{A}^{2,1}$, Alavi $\mathrm{M}^{3,1}$, Valerio $\mathrm{H}^{1,2}$, Goldberg $\mathrm{D}^{2,1}$, Hutchinson $\mathrm{SJ}^{1,2}$.

\section{AFFILIATIONS:}

1) School of Health and Life Sciences, Glasgow Caledonian University, Glasgow, UK

2) Health Protection Scotland, Glasgow, UK

3) The Kirby Institute for infection and immunity in society, University of New South Wales, Sydney, Australia

\section{CORRESPONDING AUTHOR INFORMATION:}

Name: Hamish Innes

Address: Glasgow Caledonian University, Cowcaddens Road, George Moore Building, G40BA.

Glasgow,

Email: hamish.innes@gcu.ac.uk and/or hamish.innes@nhs.net

Tel: 0141-3313915 and/or 0141-3001106.

\section{CONFLICTS OF INTEREST:}

HI reports receiving a speaker fee from Gilead Sciences, outside the submitted work. All other authors have nothing to disclose.

ABBREVIATIONS (in order of appearance):

CHC, Chronic hepatitis C; HRB, Health Risk Behaviour, NHANES, National Health and Nutritional Examination Survey; MRR, Mortality Rate Ratio; HCV, Hepatitis C Virus; MEC, Mobile Examination Centre. CDC, Centre for Disease Control. 


\section{ABSTRACT}

BACKGROUND: In resource-rich countries, chronic hepatitis $\mathrm{C}(\mathrm{CHC})$ infection is associated with a sizeable excess mortality risk. The extent to which this is due to: (a) the biological sequelae of $\mathrm{CHC}$ infection, versus b) a high concomitant burden of health risk behaviours (HRBs), is unclear.

METHODS: We used data from the 1999-2010 US National-Health-and-NutritionalExamination-Surveys (NHANES), which include detailed information on HRBs and CHC infection status. We calculated the prevalence of the five major HRBs - alcohol use; cigarette smoking, physical inactivity, unhealthy diet, and illicit drug use -according to $\mathrm{CHC}$ after adjusting for socio-demographic differences. Mortality status after survey interview was ascertained via linkage to the US National Death Index. To assess the contribution of HRBs to the excess mortality risk, we determined the all-cause mortality rate ratio (MRR) for individuals with $\mathrm{CHC}$ relative to individuals without, and then calculated the attenuation in this MRR following adjustment for HRBs.

RESULTS: This analysis included 27,468 adult participants of NHANES of which 363 tested positive for CHC. All HRBs were markedly more prevalent among individuals with $\mathrm{CHC}$ versus individuals without. $\mathrm{CHC}$ was associated with a 2.4-fold higher mortality rate after adjustment for socio-demographic factors (MRR:2.36;95\%CI:1.60-3.49). Subsequent adjustment for all five HRBs attenuated this ratio by 50.7\% to MRR:1.67(95\%CI:1.14-2.44). Higher levels of attenuation (69.1\%) were observed among individuals aged 45-70yrs, who form the target demographic for US birth cohort screening.

CONCLUSION: At least half the excess mortality risk for individuals with $\mathrm{CHC}$ in the US may be due to HRBs rather than $\mathrm{CHC}$. The remedial response to hepatitis $\mathrm{C}$ must not neglect action on HRBs if it is to fully resolve the high mortality problem in this population. 


\section{INTRODUCTION:}

Chronic hepatitis $\mathrm{C}(\mathrm{CHC})$ infection is a major global health concern, affecting approximately 80 million people worldwide.[1] $\mathrm{CHC}$ is associated with considerable excess mortality in resource-rich settings. In Western Europe, North America and Australia, allcause mortality rates are 3.1-6.7 times higher among individuals diagnosed with HCV antibodies versus the general population (after adjustment for age, sex and calendar year) [27]. The elevated mortality risk is most pronounced in younger age groups. For example, allcause mortality is 9.0 times higher than the general population among infected persons in Scotland aged 20-49 years, but only 3.7 times higher among infected persons aged $\geq 50$ years. [3]

Understanding the factor(s) driving this excess mortality risk is a pre-requisite to an effective remedial response. Currently, the extent to which the excess mortality reflects: (a) the biological sequelae of CHC infection, versus b) a high concomitant burden of health risk behaviours (HRBs), is unclear. On the one hand, $\mathrm{CHC}$ infection causes persistent inflammation and scarring of the liver, which over time can lead to liver cirrhosis and liver cancer. [8] CHC infection has also been causally linked to a wide variety of extrahepatic diseases including diabetes, non-hodgkins lymphoma and cardiovascular disease. [9-11] On the other hand, data are emerging that suggest HRBs play an important contributory role to the impaired survival of this population. Approximately a third of $\mathrm{CHC}$ patients attending liver clinics self-report a history of heavy alcohol, whilst more than half report previous injecting drug use. [12.13] Studies examining what people diagnosed with hepatitis $\mathrm{C}$ die from in resource-rich settings indicate two dominant causes of death.[14] Firstly, drug-related mortality (accounting for $18-27 \%$ of total deaths); and secondly, liver disease (accounting for $18-24 \%$ of total mortality). Of mortality due to liver disease, we previously estimated that only $55-66 \%$ is attributable to CHC in Denmark and Scotland.[15], and speculated that the residual component may reflect the consequences of excess alcohol use (which is strongly associated with liver cirrhosis and liver mortality in persons with CHC. $[16,17,13])$. Further, although cure of $\mathrm{CHC}$ is associated with a reduction in mortality risk, $[18,19]$ mortality nevertheless remains 1.9 times higher than the general population in cured patients, with health behaviours (specifically markers of heavy alcohol use and injecting drug use) being key mortality determinants. [20]

Thus far, no study has systematically examined the collective contribution of the five major 
HRBs - excess alcohol use, cigarette smoking, physical inactivity, unhealthy diet, and illicit drug use [21] - to the excess mortality risk in persons with CHC. And particularly no study has done so in a sample representative of the $\mathrm{CHC}$-infected population as a whole (i.e. most studies are confined to diagnosed individuals, thereby ignoring the appreciable proportion, typically $>50 \%$ [32], of the infected population that are unaware of their infection). Therefore, in this study, we analysed general-population data from the US continuous National Health and Nutritional Examination Survey (NHANES) which is unique in including individual-level data on: 1) baseline chronic HCV status; 2) self-reported HRBs; and 3) subsequent mortality events through to Dec 2011. Specific questions that we set out to address in this study were as follows. Firstly, what is the size of the excess mortality risk in a population-based sample (i.e. inclusive of diagnosed and undiagnosed persons), after adjusting for basic socio-demographic factors? Secondly, what are the prevalence differences in the five major HRBs according to CHC infection status? Thirdly, to what extent do any such prevalence differences in HRBs account for the excess mortality risk in US persons with $\mathrm{CHC}$ infection? 


\section{METHODS:}

\section{BRIEF DESCRIPTION OF NHANES}

The continuous National Health and Nutritional Examination Survey (NHANES) is a large cross-sectional health survey of the US population. The survey was first carried out in the year 1999 and has been repeated annually ever since. The survey sample - comprising c.5000 individuals per year - is selected through a complex multistage process that ensures generalizability to the US civilian non-institutionalised household population (see [23] for more details). Participation in NHANES entails completion of an initial household interview and/or a detailed health examination conducted in a bespoke mobile examination centre (MEC). Data collected on survey participants include, inter alia, information pertaining to: socio-economic factors; demographic factors; medical history; HRBs; and medical/physiological measurements. In addition, various laboratory tests- including tests for $\mathrm{CHC}$ and other blood borne viruses - are carried out on participant urine and blood specimens. [24] Although NHANES includes representation from all age groups, data on alcohol, drug and tobacco-related HRBs are only publicly available for participants aged $\geq 20$ years. The raw data used in this analysis can be found at: https://wwwn.cdc.gov/nchs/nhanes/Default.aspx

\section{INCLUSION CRITERIA:}

We included all adults (defined as age $\geq 20$ years at time of survey interview) who participated in NHANES from 1999 to 2010; and who completed the household interview, MEC examination and dietary questionnaire components of the survey. We excluded any individuals with unknown $\mathrm{CHC}$ infection status and/or any individual who could not be linked to the national death index. NHANES participants from years 2011 onwards were not included in this analysis because their post-survey mortality data were not available in the latest public use linked mortality file.

\section{MAJOR DATA VARIABLES}

We characterised survey participants with respect to: 1.socio-demographic factors, 2.current HRBs (i.e. HRBs present at the time of the survey interview); 3.former HRBs (HRBs present in the past but not at the time of survey interview); 4. CHC infection status; 5. comorbid medical conditions; and 6. mortality status through to 31 Dec 2011. 


\section{0: DATA ON SOCIO-DEMOGRAPHIC FACTORS:}

Socio-demographic factors included in this analysis were age; gender; income poverty; education; survey year and race. Income poverty is calculated in the NHANES datasets as the ratio of each participant's household income to the poverty threshold. The poverty threshold in turn is determined from the US Department of Health and Human Services poverty guidelines that are used to decide eligibility to a suite of federal welfare programmes.

\section{0: DATA ON HEALTH RISK BEHAVIOURS}

Excess alcohol use, cigarette smoking; physical inactivity; unhealthy diet; and illicit drug use are regarded as the major HRBs detrimental to health. We characterised each survey participant in terms of these behaviours. A distinction was drawn throughout between current HRBs (i.e. a HRB present at the time of survey interview) and past HRBs (i.e. present in the past but not at the time of survey interview). Current excess alcohol use was defined as drinking, on average, $>2$ drinks/day in the 12 months preceding the survey interview. We examined three severity levels of current excess use. These were mean consumption of: i) $>2$ but $<4$ drinks/day; ii) $\geq 4$ but $<5$ drinks/day; and iii) $\geq 5$ drinks/day, in the 12 months preceding survey examination. Participants who reported consuming "at any time in their life, five alcoholic drinks or more almost every day" were considered to be former heavy alcohol users providing their current alcohol intake was below the 5 drinks/day threshold. For all the above measures of alcohol use, one drink was defined as that containing $14 \mathrm{~g}$ of pure alcohol (equivalent to 1.75 UK units). Current drug use was defined as the use of an illicit drug at least once within the past year. We considered two types of current drug users; those who had used a needle in the last year to inject drugs and those who had not. Individuals who had not used drugs in the last year but had done so in the past were considered to be former drug users. Similarly, we distinguished between former drug users that had ever injected drugs with a needle from former drug users who had not. Changes to the drug-use questionnaire in 2005 meant that we could not keep the definition of noninjecting drug exactly the same for all survey participants. For 1999-2004 participants therefore, non-injecting drug use refers to use of "cocaine or any other street drug (excluding marijuana)", whereas for 2005-2010 participants, it refers more specifically to use of "cocaine, crack cocaine, heroin or methamphetamine". Unhealthy eating was based on the amount of fruit and vegetables the participant reported consuming in the 24-hour period prior to survey examination. We used the US Department of Agriculture food codes to distinguish 
fruits/vegetables from other foods (see eTable 1). We defined a single portion of fruit or vegetable as that which weighs $30 \mathrm{~g}$ or $80 \mathrm{~g}$ in dried or non-dried forms, respectively. We defined "healthy eating" as consumption of at least 3 distinct portions of fruit/vegetable (analogous to definitions adopted in previous studies[25]). By the same token, participants who consumed less than three portions of fruit/vegetables (or consumed $>=3$ portions, but with those portions spread out across less than three distinct fruits or vegetables) were considered in this analysis to have an "unhealthy" diet. Data on past/former unhealthy eating habits are not available in NHANES. Current physical inactivity was defined as the absence of regular moderate or vigorous physical activity at the time of the survey interview. As with illicit drug use, modifications to the physical activity questionnaire meant that inactivity was defined slightly differently according to survey year. For 1999-2004 participants, inactivity was defined as the absence of any moderate/vigorous activity in the 30 days prior to survey interview, whereas for 2005-2010 participants, inactivity was defined as reporting the absence of any moderate/vigorous activity "in a typical week". No data on former physical inactivity was available in NHANES. In relation to cigarette smoking, a participant was considered to be a current smoker, if at the time of their interview they reported smoking cigarettes "now" (either "every day" or on "some days"). Individuals who were not current smokers, but who reported smoking more than 100 cigarettes at any point in their life were categorised as former smokers.

Of note, information on cigarette smoking, alcohol consumption, physical activity and dietary intake were elicited from participants via face-to-face interviews, conducted either at the participant's home or at the NHANES MEC. Data on illicit drug use was collected with greater anonymity through a computer-assisted self-administered questionnaire carried out at the MEC.

\section{0: DATA ON CHRONIC HEPATITIS C INFECTION STATUS}

NHANES participants submit a blood sample that is later tested for viral markers, including markers of CHC, hepatitis B and human immunodeficiency virus (HIV) infection. We defined $\mathrm{CHC}$ infection as positivity for both $\mathrm{HCV}$ antibodies and HCV RNA. Individuals testing negative for $\mathrm{HCV}$ antibodies were considered to be without $\mathrm{CHC}$. Individuals testing positive for HCV antibodies but negative for HCV RNA were also considered to be without CHC. Individuals with unknown $\mathrm{CHC}$ status (as indicated by a missing or indeterminate 
result for $\mathrm{HCV}$ antibodies, or a missing result for HCV RNA if the participant tested positive for HCV antibodies) were excluded from this analysis.

\section{0: DATA ON COMORBID MEDICAL CONDITIONS}

We included data on whether the following conditions had ever been diagnosed by a doctor or other health professional: heart disease, chronic obstructive pulmonary disease; cancer and diabetes. Heart disease was defined as previous diagnosis of congestive heart failure, coronary heart disease, angina, or a prior heart attack. Chronic obstructive pulmonary disease was defined as emphysema or chronic bronchitis. Obesity was defined as having a body mass index of $\geq 30 \mathrm{~kg} / \mathrm{m}^{2}$. Current infection with other blood borne viruses was based on positivity for hepatitis B surface antigen protein and /or antibodies to HIV. Of note, testing for HIV antibodies were only carried out for participants aged 0-49 yrs at baseline, and so data are missing for a large portion of our complete sample.

\section{0: DATA ON SUBSEQUENT MORTALITY STATUS}

The vital status at 31 Dec 2011 of survey participants was ascertained through linkage to the 2015 public-use linked mortality file. This file is generated through probabilistic matching of NHANES participants to the US National Death Index. [26]

\section{STATISTICAL ANALYSIS}

Our analysis comprised two strands: Firstly assessment of the prevalence difference in HRBs according to $\mathrm{CHC}$ infection, and secondly assessment of the contribution that these prevalence differences make to the excess mortality risk. Both analyses were carried out initially on the whole cohort, and then specifically for participants aged 45-70 years at baseline. This latter subgroup analysis was intended to mirror the eligibility criteria for onetime HCV antibody testing, currently recommended for individuals in the US born between 1945 and 1965. [27] All analyses took account of the multistage complex sampling design of NHANES.[23] Each participant was assigned the sample weight provided on the dietary questionnaire files (as this was our smallest analysis subpopulation). When combining participants from different survey cycles (i.e. years 1999-2010), we re-calibrated these weights so that our final pooled sample mirrored the socio-demographic composition of the 
US civilian non-institutionalised population at the time of year 2000 census (see [28] for further details). Variance estimates were adjusted via Taylor series linearization throughout.

ANALYSIS 1: PREVALENCE OF HRBS ACCORDING TO CHC INFECTION STATUS

We calculated the prevalence of current and former HRBs in participants according to $\mathrm{CHC}$ infection status. Each prevalence estimate was standardised for baseline age, race, education and gender, using a standard population derived from the age/race/education/gender distribution of survey participants with CHC infection (see eTable 1). In this way, for participants with $\mathrm{CHC}$ infection, our estimates reflect the actual observed prevalence of each $\mathrm{HRB}$, whereas for participants without $\mathrm{CHC}$, our estimates reflect the expected prevalence given the same socio-demographic distribution as per the $\mathrm{CHC}$ infected population. Individuals missing data for a given HRB were not included in the prevalence estimate for that $\mathrm{HRB}$, but were included in the prevalence estimate for other HRBs where the requisite data was not missing - as a result, each HRB prevalence estimate can be based on a slightly different denominator.

\section{ANALYSIS 2: CONTRIBUTION OF HRBS TO EXCESS MORTALITY IN PERSONS WITH CHC}

A Poisson regression model was fitted to determine the mortality rate ratio (MRR) for CHC infection versus no $\mathrm{CHC}$ infection after adjustment for socio-demographic factors. This initial model is referred to as the base model. We then determined the $\%$ attenuation (i.e. the $\%$ reduction) in the base model MRR following further adjustment for: comorbid medical conditions; former HRBs; current HRBs; and former+current HRBs. Participants missing data for one or more covariates were included in regression models via the generation of missing indicator variables. Thus, this ensured that the base model and all further adjustment models were based on the same set of survey participants. 


\section{RESULTS:}

\section{DESCRIPTION OF FINAL SAMPLE:}

29,130 participants met our inclusion criteria, 1631 (5.6\%) were then excluded on account of missing CHC infection status, and a further 31 (0.1\%) participants were discounted because their mortality status at Dec 2011 could not be ascertained. The final sample therefore was 27,468 individuals, of which 363 (weighted prevalence: 1.2\%) had CHC infection at baseline. The complete breakdown of the cohort in terms of socio-demographic factors, comorbid medical conditions and HRBs is shown in eTable 2. Relative to those without CHC, participants with $\mathrm{CHC}$ were more likely to: be older; be male; be non-hispanic black, be living below the poverty threshold, and to not have more than a high school education, (see Table.1). At the end of follow-up, 6.2 years on average after the baseline survey interview, $2599(9.5 \%)$ participants in our sample had died (43 of these deaths were among persons with CHC infection - see eTable.3). Crude mortality rates by CHC status are shown in eTable 4. In our final sample, the proportion of participants missing data for a given covariate was low at $0-6 \%$ (see eTable 2). The two exceptions to this were data on illicit drug use (which was missing for $25.5 \%$ of participants) and data on HIV infection status (missing for $38.8 \%$ of participants).

\section{ANALYSIS 1 - PREVALENCE OF HRBS ACCORDING TO CHC INFECTION STATUS}

HRBs were more prevalent among individuals with $\mathrm{CHC}$ infection versus individuals without. This applied particularly to current HRBs. Current excess alcohol use was 2.3 times more prevalent $(18.7 \%$ for $\mathrm{CHC}$-infected versus $8.3 \%$ for $\mathrm{CHC}$ uninfected; $\mathrm{p}<0.001)$. Current cigarette smoking was 2.3 times as prevalent $(63.8 \%$ for $\mathrm{CHC}$-infected versus $28.2 \%$, $\mathrm{p}<0.001)$; Current injecting drug use was ninety-three times as prevalent $(9.3 \%$ for CHCinfected versus $0.1 \%$ for $\mathrm{CHC}$ uninfected, $\mathrm{p}=0.001$ ). Current non-injecting drug use was 3.4 times as prevalent $(16.2 \%$ for $\mathrm{CHC}$-infected versus $4.7 \%$ for $\mathrm{CHC}$ uninfected, $\mathrm{p}<0.001)$. Comparable differences were observed in our subgroup analysis of patients aged 45-70 years at baseline (see Table 2). The prevalence difference (i.e. the absolute difference in prevalence between participants with $\mathrm{CHC}$ versus participants without) is shown for each $\mathrm{HRB}$ in descending order in Figure.1 


\section{ANALYSIS 2; CONTRIBUTION OF HRBS TO EXCESS MORTALITY IN PERSONS WITH CHC}

In our final sample of 27,468 survey participants, the MRR comparing individuals with CHC infection to individuals without, after adjustment for socio-demographic factors alone, was 2.36 (95\% CI: 1.60-3.49). After adjusting for socio-demographic factors + comorbid medical conditions (see model \#17), the MRR attenuated only marginally, by $0.7 \%$, to 2.35 (95\% CI: 1.62-3.41). Similarly, when adjusting for socio-demographic factors + former HRBs (see model\#18), the MRR attenuated minimally to 2.27 (95\% CI: 1.47-3.52). Conversely, when adjusting for socio-demographic factors + current HRBs (model \#19), the MRR attenuated by $51.5 \%$ to 1.66 (95\% CI: 1.19-2.32). The single HRB associated with greatest attenuation was current cigarette smoking ( $30 \%$ attenuation following adjustment for this behaviour alone). Total HRB adjustment (i.e. adjustment for former and current HRBs) attenuated the MRR by $50.7 \%$ to 1.67 (95\% CI: $1.14-2.44)$.

In our subgroup analysis of individuals aged $45-70$ years at baseline $\underline{(\mathrm{N}=10,810)}$, the sociodemographic-adjusted MRR was smaller than for the full cohort at 1.68 (95\% CI: 0.89-3.20). Attenuation due to HRB adjustment was even more pronounced in this subgroup versus the full cohort. For instance, adjustment for current HRBs attenuated the MRR by $69.6 \%$, whilst adjustment for current + former HRBs attenuated the MRR by $69.1 \%$ (see Table 3 ). 


\section{DISCUSSION:}

\section{MAIN FINDINGS:}

The existence of a substantial excess mortality risk for individuals with $\mathrm{CHC}$ infection in resource-rich countries [2-7] is a major clinical and public health concern. Although the detrimental effect of $\mathrm{CHC}$ itself is the most obvious explanation for this phenomenon, other factors may be contributing too. In this study, we used unique data from a large US community survey to examine the extent to which HRBs contribute to excess mortality in this population. As expected, we observed a considerable excess mortality risk for individuals with $\mathrm{CHC}$ infection after adjusting for socio-demographic factors. Specifically, the all-cause mortality rate for individuals with $\mathrm{CHC}$ was 2.4 times higher than for individuals without $\mathrm{CHC}$ (an excess which, if extrapolated to the US population as a whole, equates to $\sim 39,000$ surplus CHC deaths every year - see Appendix A). However, the key finding from this study is that this excess mortality risk attenuated considerably - by $50.7 \%$ _following subsequent adjustment for all HRBs. This suggests that although CHC is a well-known cause of hepatic and extrahepatic disease, half the mortality excess may actually reflect the consequences of HRBs rather than CHC itself. The impact of ameliorating HRBs in the CHC-infected population could therefore be considerable, and so it is striking that the evidence-base on this topic is so thin. In a recent systematic review, Doyle et al could identify only two RCTs for an alcohol reduction intervention in patients with HCV. [29] In like vein, we were unable to identify a single RCT evaluating a smoking cessation intervention for patients with HCV in our own brief literature search (see appendix B). Overall this study cautions that advancements in antiviral therapy [30] aside- a sizeable excess mortality risk is likely to persist for individuals with past/present $\mathrm{CHC}$ unless more attention is paid to tackling coexisting HRBs.

\section{US BIRTH COHORT SCREENING:}

In 2012, the Centre for Disease Control (CDC) recommended that all US individuals born between 1945 and 1965 receive one-time testing for HCV.[27]. When we restricted our analysis to individuals aged 45-70 years (i.e. to roughly mirror the age range that birth cohort screening will in practice be applied to) we observed even higher levels of attenuation to that of the full cohort (69.1\%), and similarly saw that most of the attenuation was driven by adjustment for current HRBs (particularly cigarette smoking). Although this result does not undermine birth cohort screening as such (i.e. whilst the MRR for this subgroup was not 
statistically significant, this probably reflects a lack of statistical power as opposed to a real non-effect of $\mathrm{CHC}$ on mortality), they do persuade that addressing HRBs should form a strong component of this intervention. At present, this is arguably not the case. Although the $\mathrm{CDC}$ do recommend that those testing positive for $\mathrm{HCV}$ be advised to decrease their alcohol consumption, they concede that the evidence-base on how to actually deliver this advice is limited. [27] Further US birth cohort screening omit guidance on counselling for other relevant HRBs (notably for cigarette smoking, which led to the strongest attenuation in the excess mortality risk for this population).

\section{LIMITATIONS OF STUDY}

There are several limitations of this study. We had no data on individuals with $\mathrm{CHC}$ infection clearing infection via antiviral therapy during follow-up. In theory this could bias the size of the excess mortality risk towards the null. However, the rate of clearing $\mathrm{CHC}$ through antiviral treatment was minimal in the US during the time period of this analysis - only about 1.4 SVRs per year for every 100 infected persons (see Appendix C) - and so is unlikely to affect our conclusions. A second limitation relates to selection bias; survey participants who completed both the mobile examination and dietary components of this survey (i.e. the inclusion criteria of this study) may differ from those who did not. However, the survey weights assigned to survey participants are calibrated to adjust for differential response by socio-demographic factors,[31] and in any case non-response rates were reasonably low (i.e. $67 \%$ of those invited to participate in NHANES fulfilled the inclusion criteria of this study see eFig.1). Thirdly, NHANES is a survey of the civilian non-institutionalised population and therefore excludes individuals who are homeless or in prison (two subpopulation where the prevalence of HCV is high[32-33]). Thus, whilst NHANES may not perfectly represent the general CHC infected population in the US, it will provide a far more representative sample than the alternative of diagnosis/treatment cohorts. Fourthly, some individuals in our cohort were missing data for one or more HRBs. Mostly the proportion with missing data was low $(<5 \%)$, but it was more common in relation to data on illicit drug use (where $25.5 \%$ of our final sample were missing data on this HRB). The high frequency of missing drug use data was due to the NHANES survey protocol rather than individuals choosing to not respond to the requisite questions. For the 1999-2006 and 2007-2008 survey years, questions relating to illicit drug use were not posed to participants aged $\geq 60$ years and $\geq 70$ years, respectively. It is possible that the age/survey year patterning of this missing data could have caused bias with respect to the association between illicit drug use and mortality risk. Fifthly, this study would 
ideally have stratified \% attenuation across a number of socio-demographically defined subgroups. However, low statistical power (stemming from only 43 deaths in the CHC infected population overall) precluded us from doing this in a robust way. For a similar reason, we were not able to stratify $\%$ attenuation by cause of death. That said, we did examine the categories of death contributing most to the excess mortality in $\mathrm{CHC}$ participants (see Appendix D), and found that $30 \%$ of the excess was due to deaths from accidents (which, prima facie, is consistent with a strong HRB contribution). However, this supplementary analysis is again limited by the small number of deaths, and the broad causeof-death categories themselves (the selection of which, we had no control over). A final limitation is that the HRB data were measured at a single cross-sectional time point. Longitudinal data would have been superior in that it would have allowed us to take account of any changes in HRBs occurring over the course of follow-up. Previous work has suggested that analysing HRBs on the basis of cross-sectional data, as opposed to longitudinal data, will understate contribution of HRBs on mortality - particularly with regard to the contribution of poor diet and physical inactivity [34].

\section{CONSISTENCY WITH PREVIOUS NHANES RESEARCH}

Our analysis is consistent with previous studies of NHANES data, establishing: a) a heightened prevalence of current alcohol use among persons with hepatitis $C$ [35]; and b) that alcohol use is an independent predictor of mortality among persons with hepatitis $C$ [36]. More notably however, these findings are consistent with a study by El-Kamary et al [37] which also indicated substantial attenuation in the mortality excess following adjustment for a broad range of co-factors. However, there were some important limitations of this study. Firstly, it was based on historical NHANES III data (the interviews for which were carried 20-25 years ago between 1988 and 1994); as such the data may not be representative of individuals living with $\mathrm{CHC}$ infection today. Secondly, their analysis did not include detailed data on HRBs such as dietary, exercise, past alcohol use, and injecting drug use history. The absence of these data precludes a comprehensive assessment of the total impact of HRBs. Thirdly, El-Kamary et al asked a fundamentally different question of the data to that of this study - namely, does HCV remain independently associated with higher mortality even after adjusting for all relevant confounders? As such, they did not report attenuation following adjustment for HRBs as we have done here.

\section{SUMMARY}


In conclusion, individuals with CHC infection in the US exhibit a considerable excess mortality risk. Yet, about half of this excess may reflect high levels of HRBs as opposed to the effects of CHC infection itself. This study therefore highlights the importance of a publichealth response to hepatitis $\mathrm{C}$ that includes action on HRBs as well as access to antiviral therapy. 


\section{REFERENCES}

[1] Gower E; Estes C, Blach S, Razavi-Shearer K, Razavi H. Global epidemiology and genotype distribution of the hepatitis C virus infection. J Hepatol 2014;61:S45-S57. [2] Aspinal EJ, Hutchinson SJ, Janjua NZ, Grebely J, Yu A, Alavi M, et al. Trends in mortality after diagnosis of hepatitis $\mathrm{C}$ virus infection: an international comparison and implications for monitoring the population impact of treatment.

[3] McDonald SA, Hutchinson SJ, Schnier C, McLeod A, Goldberg DJ. Estimating the number of injecting drug users in Scotland's HCV-diagnosed population using capturerecapture methods. Epidemiol Infect 2014; 142:200-7.

[4] Duberg AS, Torner A, Davidsdottir L, Aleman S, Blaxhult A, Svensson A, et al. Cause of death in individuals with chronic HBV and/or HCV infection, a nationwide community-based register study. J Viral Hepat; 2008;15:538-50.

[5] Amin J, Law M; Bartlett M, Kaldor JM, Dore GJ. Causes of death after diagnosis of hepatitis B or hepatitis C infection: a large community-based linkage study. Lancet 2006;368:938-45.

[6] McDonald SA, Hutchinson SJ, Bird SM, Mills PR, Dillon J, Bloor M, et al. A populationbased record linkage study of mortality in hepatitis C-diagnosed persons with or without HIV coinfection in Scotland. Stat Methods Med Res 2009;18:271-83.

[7] Kristansen MG, Lochen ML, Gutteberg TJ, Mortensen L, Eriksen BO, Florholmen J. Total and cause-specific mortality rates in a prospective study of community-acquired hepatitis C virus infection in northern Norway. J Viral Hepat 2011; 18:237-44.

[8] Marcellin P, Asselah T, Boyer N. Fibrosis and disease progression in hepatitis C. Hepatology 2002; 36:S47-S56.

[9] Su TH, Liu CJ, Tseng TC, Chou SW, Liu CH, Yang HC. Hepatitis C viral infection increases the risk of lymphoid-neoplasm: a population-base cohort study. Hepatology 2016;63:721-730.

[10] Cacoub P, Comarmond C, Domont F, Savey L, Desbois AC, Saadoun D.

Extrahepatic manifestations of chronic hepatitis $\mathrm{C}$ virus infection. Ther Adv Infect Dis. $2016 ; 3: 3-14$

[11] Domont F, Cacoub P. Chronic hepatitis C virus infection, a new cardiovascular risk factor? Liver Int 2016; doi: 10.1111/liv.13064

[12] Boscarino JA, Moorman AC, Gordon SC, Rupp LB, Spradling PR, Teshale EH, et al. Predictors of poor mental and physical health status among patients with chronic hepatitis $\mathrm{C}$ infection: the chronic hepatitis cohort study (CHeCS). Hepatology 2015; 61:802-11. 
[13] Innes HA, Hutchinson SJ, Barclay S, Cadzow E, Dillon JF, Fraser A, et al. Quantifying the fraction of cirrhosis attributable to alcohol among chronic hepatitis $\mathrm{C}$ virus patients: implications for treatment cost-effectiveness. Hepatology 2013; 57:451-460.

[14] Grebely J, Dore GJ. What is killing people with hepatitis C virus infection. Semin Liver Dis. 2011;31:331-9.

[15] Innes H, Hutchinson SJ, Obel N, Christensen PB, Aspinall EJ, Goldberg DJ, et al. Liver mortality attributable to chronic hepatitis $\mathrm{C}$ virus infection in Denmark and Scotland- using spontaneous resolvers as the benchmark comparator. Hepatology 2016;63:1506-1516.

[16] Harris DR, Gonin R, Alter HJ, Wright EC, Buskell ZJ, Hollinger FB, et al. The relationship of acute transfusion-associated hepatitis to the development of cirrhosis in the presence of alcohol abuse. Ann Intern Med 2001;134:120-4.

[17] Hutchinson SJ, Bird SM, Goldberg DJ. Influence of alcohol on the progression of hepatitis C virus infection: a meta-analysis. Clin Gastroenterol Hepatol. 2005;3:1150-9. [18] Innes HA, McDonald SA, Dillon JF, Allen S, Hayes PC, Goldberg DJ, et al. Towards a more complete understanding of the association between a hepatitis $\mathrm{C}$ sustained viral response and cause-specific outcomes. Hepatology 2015; 62:355-64.

[19] Van der Meer AJ, Veldt BJ, Feld JJ, Wedemeyer H, Dufour JF, Lammert F, et al. Association between sustained virological response and all-cause mortality among patients with chronic hepatitis C and advanced hepatic fibrosis. JAMA. 2012; 308: 2548-2593.

[20] Innes H, McDonald S, Hayes P, Dillon JF, Allen S, Goldberg D, et al. Mortality in hepatitis $\mathrm{C}$ patients who achieve a sustained viral response compared to the general population. J Hepatol. 2017;66:19-27.

[21] Spring B, Moller AC, Coons MJ. Multiple health behaviours: overview and implications. J Public Health (Oxf). 2012;34 Suppl 1:i3-10.

[22] Volk ML. Antiviral therapy for hepatitis C: why are so few patients being treated?. J Antimicrob Chemother 2010;65:1327-9.

[23] Key concepts about NHANES Survey Design https://www.cdc.gov/nchs/tutorials/nhanes/surveydesign/sampledesign/info1.htm. Accessed March 2017.

[24]National Centre for Health Statistics. National Health and Nutritional Examination Survey overview. Available at:

https://www.cdc.gov/nchs/data/nhanes/nhanes_13_14/nhanes_overview_brochure.pdf Accessed March 2017. 
[25] Elwood P, Galante J, Pickering J, Palmer S, Bayer A, Ben-Shlomo Y, et al. Healthy lifestyles reduce the incidence of chronic diseases and dementia: evidence from the Caerphilly cohort study. PLoS One. 2013; 8:e81877

[26] National Center for Health Statistics. Office of Analysis and Epidemiology, Public-use Linked Mortality File, 2015. Hyattsville, Maryland. (Available at the following address: http://www.cdc.gov/nchs/data_access/data_linkage/mortality.htm [27] Smith BD, Morgan RL, Beckett GA, Falck-Ytter Y, Holtzman D, Teo CG, et al. Recommendations for the identification of chronic hepatitis $\mathrm{C}$ virus infection among persons born during 1945-65. MMWR Recomm Rep. 2012;61:1-32.

[28] When and how to construct weights when combining survey cycles. Available at. https://www.cdc.gov/nchs/tutorials/nhanes/surveydesign/weighting/task2.htm. Accessed March 2017.

[29] Doyle JS, Hunt D, Aspinall EJ, Hutchinson SJ, Goldberg DJ, Nguyen T, et al. A systematic review of interventions to reduce alcohol consumption among individuals with chronic HCV. J Hepatol 2014; 60:S314-S315.

[30] Pawlotsky JM. New hepatitis C therapies: the toolbox, strategies and challenges. Gastroenterology 2014;146:1176-92.

[31] Mirel LB; Mohadjer LK; Dohrmann SM, Clark J, Burt VL, Johnson CL, et al. National Health and Nutrition examination survey: estimation procedures, 2007-2010. Vital and health statistics. 2013. Series 2, number 160.

[32] Nyamathi AM, Dixon EL, Robbins W, Smith C, Wiley D, Leake B, et al. Risk factors for hepatitis C virus infection among homeless adults. J Gen Intern Med. 2002;17:134-143. [33] Fox RK, Currie SL, Evans J, Wright TL, Tobler L, Phelps B, et al. Hepatitis C virus infection among prisoners in the California state correctional system. Clin Infect Dis 2005;41:177-86.

[34] Stringhini S, Sabia S, Shipley M, Brunner E, Nabi H, Kvimaki M, Singh-Manoux A. Association of socioeconomic position with health behaviours and mortality. JAMA 2010; 303:1159-66.

[35] Taylor AL, Denniston MM, Klevens RM, McKnight-Eily LR, Jiles RB. Association of hepatitis C virus with alcohol use among U.S Adults: NHANES 2003-2010. in press. Am J Prev Med. 2016 doi: 10.1016/j.amepre.2016.02.033.

[36] Younossi ZM, Zheng L, Stepanova M, Venkatesan C, Mir HM. Moderate, excessive or heavy alcohol consumption: each is significantly associated with increased mortality in patients with chronic hepatitis C. Aliment Pharmacol Ther 2013;37:703-709. 
[37] El-Kamary SS, Jhaveri R, Shardell MD. All-cause, liver-related, and non-liver-related mortality among HCV-infected individuals in the general US population. Clin Infect Dis.

$2011 ; 53: 150-7$.

Fig.1 Standardised prevalence differences for major former and current health risk behaviours, between participants with chronic hepatitis $C$ and participants without.

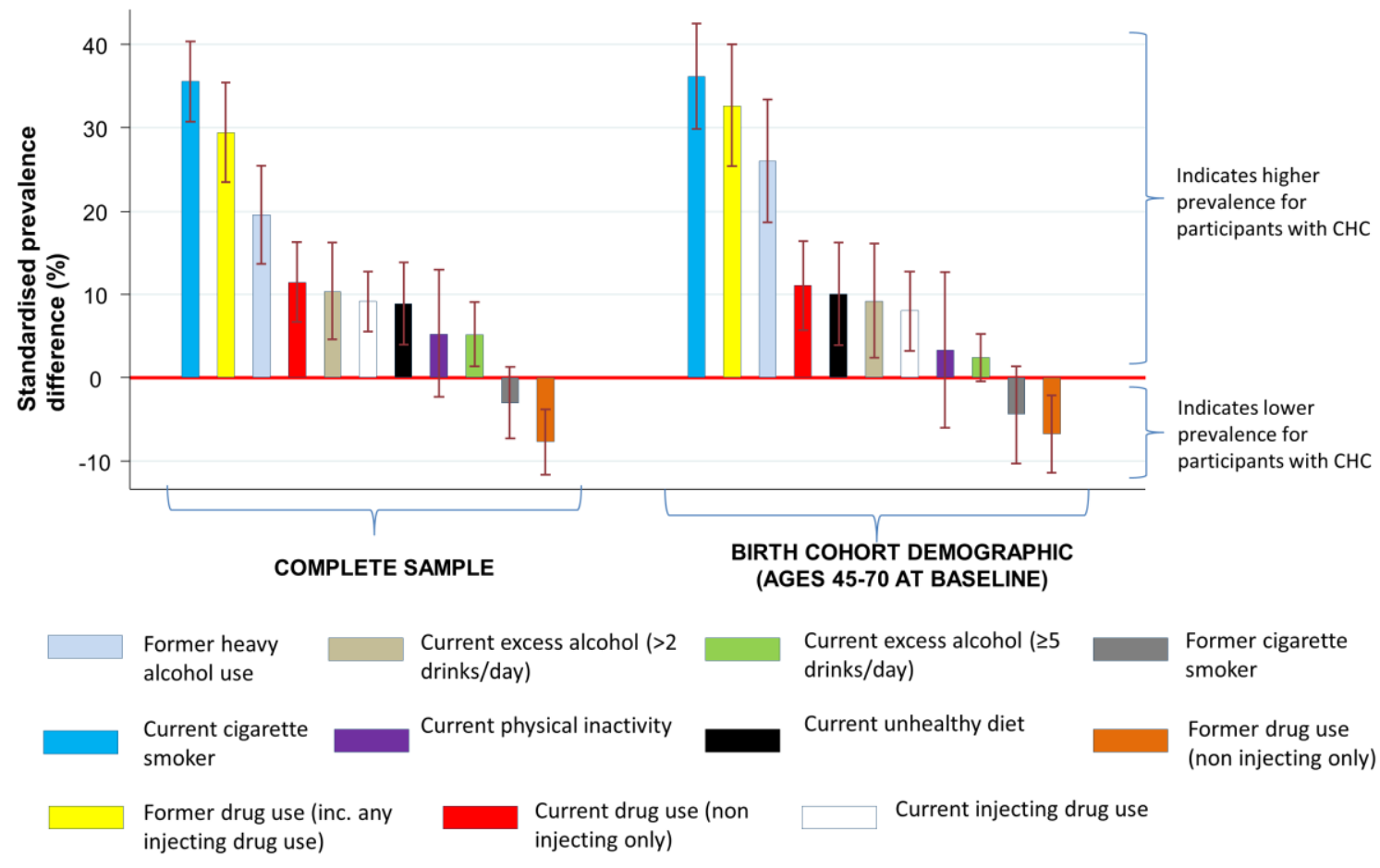

* Standardised prevalence difference calculated for each HRB, by subtracting the \%-prevalence for participants with CHC (see Table 2) from the standardised \% -prevalence for participants without CHC (see Table 2). 